\title{
A Retrospective Analysis over the Forensic Files in one of the Dental Faculty Archives in Turkey
}

\section{Humeyra Kocaelli ${ }^{1}$ and Feryal Karaman ${ }^{2 *}$}

${ }^{1}$ Dentistry Faculty, Department of Oral Surgery, Istanbul University, Turkey

${ }^{2}$ Institute of Forensic Sciences, Istanbul University, Turkey

\section{Introduction}

Founded in 1453, Istanbul University is one of the oldest institutions of higher learning in the world. Its Faculty of Dentistry is the first faculty of the University and celebrated its hundredth anniversary in 2008, however, forensic dental records for the last 25 years only are available in the 100 year-old Faculty archive.

It is well known that the quality of records is extremely important in forensic sciences [1]. Dental professionals have a major role to play in keeping accurate dental records and providing all necessary information [2]. Due to the lack of sufficient forensic odontology lectures in the dentistry faculties, some problems may occur. When dentists complete their education without having any knowledge about forensic odontology, they cannot be in a position of investigating, observing, commenting and preparing the proper report. This situation may sometimes lead to misjudgment about the reports prepared by the dentists in courts, which can have serious effects on legal verdict.

The aim of this study is to investigate and improve the quality of the forensic files over a 25 -year period in the Faculty of Dentistry, Istanbul University, and to find out how the progress of the forensic sciences reflect the forensic records in that time period. Additionally, we aim to determine if there are some mistakes committed during the preparation of forensic reports and if there are certain points requiring further scrutiny.

\section{Materials and Methods}

In this study, all files $(\mathrm{n}=925)$ were kept under the name "Forensic Cases" and those from a period of 25 years (between 22 February 1984 and 31 December 2008) were examined, with approval of the Faculty Deanship, Istanbul University. All forensic cases were evaluated according to the dates and departments which referred the files.

Patient claims, trauma, malpractice cases and related reports were also assessed. Traumas were scrutinized separately and classified under the titles of type, reason, localization, complications, applied treatments and the final reports. Furthermore, matters required by the judicial departments which demanded expert opinions were also looked into.

\section{Results}

It was found out that all the files were not composed purely of forensic cases and the official letters of various kinds exchanged between the faculty and the government departments were also included unnecessarily (albeit by mistake) in these files.

Of 925 files, $269(29.08 \%)$ were cases of traumas and $119(12.86 \%)$ of malpractice. Additionally, 75 requests of expert report, 13 checkup request of the arrested persons, 30 letters among the official departments regarding check-up and investigations and prices, and 115 patient requests and claims, totaling 233 cases, were included under the name "miscellaneous files" which accounted for $25.18 \%$. In two files, two letters of appreciation written by two patients were also found.
There were $304(32.86 \%)$ files under the name of "missing files" in which 13 of them had no name, 14 had no departmental reference and 277 had no definite subject. It was also found out that a period of 3 years between 1989 and 1991 did not exist in the archive, thereby making our survey applicable for a period of 22 years.

Distribution of file types according to the years is shown in Table 1. Classification of trauma cases is shown in Table 2. Intermaxillary fixation was performed on 69 of trauma cases, 13 miniplate fixation

\begin{tabular}{|c|c|c|c|c|c|c|}
\hline Years & Trauma & Malpractice & Miscellaneous & Missing Files & Total & $\%$ \\
\hline 1984 & & & & 5 & 5 & 0.54 \\
\hline 1985 & 16 & 1 & 3 & 78 & 98 & 10.59 \\
\hline 1986 & 9 & 1 & 4 & 99 & 113 & 12.21 \\
\hline 1987 & 8 & 1 & 1 & 73 & 83 & 8.97 \\
\hline 1988 & 40 & 1 & & 30 & 71 & 7.67 \\
\hline 1989 & _ & _ & _ & _ & _ & _ \\
\hline 1990 & _ & _ & _ & _ & _ & _ \\
\hline 1991 & _ & _ & _ & _ & - & _ \\
\hline 1992 & 7 & 2 & 6 & 1 & 16 & 1.72 \\
\hline 1993 & 16 & 5 & 7 & 3 & 31 & 3.35 \\
\hline 1994 & 9 & 1 & 3 & 2 & 15 & 1.62 \\
\hline 1995 & 9 & 2 & 9 & 1 & 21 & 2.27 \\
\hline 1996 & 8 & 3 & 6 & 1 & 18 & 1.94 \\
\hline 1997 & 4 & 4 & 4 & 1 & 13 & 1.40 \\
\hline 1998 & 11 & 6 & & 1 & 18 & 1.94 \\
\hline 1999 & 13 & 5 & 3 & 2 & 23 & 2.48 \\
\hline 2000 & 7 & 4 & 12 & _ & 23 & 2.48 \\
\hline 2001 & 13 & 5 & 5 & _ & 23 & 2.48 \\
\hline 2002 & 17 & 6 & 3 & 1 & 27 & 2.91 \\
\hline 2003 & 7 & 10 & 19 & _ & 36 & 3.89 \\
\hline 2004 & 12 & 6 & 21 & _ & 39 & 4.21 \\
\hline 2005 & 12 & 7 & 19 & 2 & 40 & 4.32 \\
\hline 2006 & 8 & 9 & 40 & 2 & 59 & 6.37 \\
\hline 2007 & 16 & 15 & 29 & 1 & 61 & 6.59 \\
\hline 2008 & 27 & 25 & 39 & 1 & 92 & 9.94 \\
\hline \multirow{2}{*}{$\begin{array}{l}\text { Grand } \\
\text { total }\end{array}$} & & & & & & \\
\hline & 269 & 119 & 233 & 304 & 925 & \\
\hline$\%$ & 29.08 & 12.86 & 25.18 & 32.86 & 100 & \\
\hline
\end{tabular}

Table 1: Distribution Of The Studied Files According To The Years.

*Corresponding author: Feryal Karaman, Institute of Forensic Sciences, Istanbul University, Turkey, Tel: +90 532 3263190; E-mail: feryalkaraman@hotmail.com

Received April 06, 2012; Accepted June 12, 2012; Published June 14, 2012

Citation: Kocaelli H, Karaman F (2012) A Retrospective Analysis over the Forensic Files in one of the Dental Faculty Archives in Turkey. J Forensic Res 3:153. doi:10.4172/2157-7145.1000153

Copyright: $\odot 2012 \mathrm{Kocaelli} \mathrm{H}$, et al. This is an open-access article distributed unde the terms of the Creative Commons Attribution License, which permits unrestricted use, distribution, and reproduction in any medium, provided the original author and source are credited. 
Citation: Kocaelli H, Karaman F (2012) A Retrospective Analysis over the Forensic Files in one of the Dental Faculty Archives in Turkey. J Forensic Res 3:153. doi:10.4172/2157-7145.1000153

Page 2 of 3

\begin{tabular}{|l|l|l|l|l|l|l|}
\hline & Traffic Accidents & Strike & Fire Arms & Falling Down & Accidental Traumas \\
\hline Number of Cases & 40 & 110 & 4 & 1 & 114 \\
\hline$\%$ & 14.86 & 40.89 & 1.48 & 0.37 & 269 \\
\hline
\end{tabular}

Table 2: Classification Of The Cases According To The Trauma Types.

\begin{tabular}{|c|c|c|c|c|c|c|}
\hline \multirow[b]{2}{*}{ Year } & \multirow[b]{2}{*}{ Dean } & \multirow{2}{*}{\begin{tabular}{|l} 
Police Dept. \\
Prosecutor
\end{tabular}} & \multirow[b]{2}{*}{ Court } & \multirow{2}{*}{\begin{tabular}{|l} 
Other \\
Departments
\end{tabular}} & \multirow{2}{*}{$\begin{array}{l}\text { Not } \\
\text { mentioned }\end{array}$} & \multirow[b]{2}{*}{ Total } \\
\hline & & & & & & \\
\hline 1984 & - & 2 & 3 & & & 5 \\
\hline 1985 & - & 52 & 42 & 3 & 1 & 98 \\
\hline 1986 & - & 77 & 35 & - & 1 & 113 \\
\hline 1987 & - & 67 & 13 & 3 & - & 83 \\
\hline 1988 & - & 59 & 9 & 3 & - & 71 \\
\hline 1989 & - & - & - & - & - & - \\
\hline 1990 & - & - & - & - & - & - \\
\hline 1991 & - & - & - & - & - & - \\
\hline 1992 & 2 & 6 & 7 & - & 1 & 16 \\
\hline 1993 & 2 & 16 & 8 & 5 & - & 31 \\
\hline 1994 & - & 8 & 7 & - & - & 15 \\
\hline 1995 & 3 & 8 & 9 & - & 1 & 21 \\
\hline 1996 & 1 & 11 & 4 & 1 & 1 & 18 \\
\hline 1997 & 1 & 7 & 5 & - & _ & 13 \\
\hline 1998 & - & 4 & 12 & 1 & 1 & 18 \\
\hline 1999 & 2 & 4 & 14 & 1 & 2 & 23 \\
\hline 2000 & - & 7 & 12 & 4 & - & 23 \\
\hline 2001 & - & - & 21 & 2 & - & 23 \\
\hline 2002 & - & - & 25 & 1 & 1 & 27 \\
\hline 2003 & 13 & 3 & 20 & - & - & 36 \\
\hline 2004 & 20 & 3 & 14 & 1 & 1 & 39 \\
\hline 2005 & 16 & 9 & 13 & 1 & 1 & 40 \\
\hline 2006 & 17 & 8 & 24 & 8 & 2 & 59 \\
\hline 2007 & 33 & 1 & 19 & 7 & 1 & 61 \\
\hline 2008 & 26 & 17 & 35 & 14 & - & 92 \\
\hline Grand Total & 136 & 369 & 351 & 55 & 14 & 925 \\
\hline$\%$ & 14.70 & 39.89 & 37.94 & 5.94 & 1.51 & 100 \\
\hline
\end{tabular}

Table 3: Distribution of the Received Cases According to the Government Departments.

on 9 patients, partial arch-bar on the teeth of five patients, and wire fixation on one patient.

Classification of the cases received according to the government departments is shown in Table 3. Of total 369 cases (39.89\%), 214 claim files stayed just in the Police Station and 155 were sent to the court. Of these cases, 351 (37.94\%) were put on trial and 83 required in-depth examination in The State Institute of Forensic Science. 136 (14.70\%) cases had arrived to the Deanship of the Faculty. It is seen that, patients generally prefer to apply to police stations instead of university for claims. Police stations transferred the cases to the courts, and courts required expert reports. It shows that all these cases are arriving to university mostly from indirect ways.

In our research, 119 numbers of malpractice cases were evaluated. Their classification is shown according to malpractice cases in Table 4. Fifty-seven malpractice cases were sent to the court and in-depth examination was required for 14 of them in the department of forensic science; 18 malpractice cases were directly sent to the Deanship to be solved while 15 cases were referred to the public prosecutor. It was found out that only one particular case evaluated by the Forensic Science Institute took around 10 years as a malpractice case in the court and this was the only file in which the doctor was found to be faulty among the scanned files of the last 25 years. Most malpractice cases consisted of wrong prosthesis $(45 ; 37.81 \%)$, wrong surgical applications $(29$; $24.36 \%)$, faulty orthodontic treatment $(9 ; 7.56 \%)$, improper implant applications $(8 ; 6.72 \%)$, wrong periodontal treatment $(5 ; 4.21 \%)$, and wrong teeth treatment $(5 ; 4.21 \%)$. Additionally, there were nine cases of mistreatment to the patients and nine (7.56\%) malpractice cases for which reasons were not known. These cases were also referred to the courts.

\section{Discussion}

During the survey, it was determined that 285 of the 304 files which consisted of missing documents belonged to the cases dating before the year 1990. We are in the opinion that those kinds of files were not taken into the consideration seriously in the former years. Additionally, the missing files belonging to the 3 year-period (1989-1991) also reveal the fact that not only the filing but also keeping them safe is also very important. It showed that filing and keeping the systems safe were done more seriously, especially after 1992, suggesting that awareness of the importance of proper filing showed a tendency to increase. When the related official departments were taken into consideration as to the cases and their distributions, it found out that the requests and claims made to the deanship started from 1992 onwards and an obvious 
Citation: Kocaelli H, Karaman F (2012) A Retrospective Analysis over the Forensic Files in one of the Dental Faculty Archives in Turkey. J Forensic Res 3:153. doi:10.4172/2157-7145.1000153

Page 3 of 3

\begin{tabular}{|c|c|c|c|c|c|c|c|c|c|}
\hline & & & & & & Conservative & Mistreatment & & Total \\
\hline & Prothesis & Surgery & Implantology & Orthodonty & Periodontology & Treatment & to patients & Unknown & \\
\hline Number of cases & 45 & 29 & 8 & 9 & 5 & 5 & 9 & 9 & 119 \\
\hline$\%$ & 37.81 & 24.36 & 6.72 & 7.56 & 4.21 & 4.21 & 7.56 & 7.56 & 100 \\
\hline
\end{tabular}

Table 4: Classification According To Malpractise Cases.

increase was seen by 2003. This increment may be related with the ISO9001: 2000 Certificate Faculty of Dentistry of Istanbul University that was granted in 2004 .

Before 1992, the citizens generally used to start the first step by applying to the police station. In the later years, the cases started to be sent to the courts and the number of the cases sent to the court increased considerably after the year 2000 . The malpractice cases investigated were found to be less in number in the earlier years, however, they increased in later years and, after 2000, an obvious increase was seen. The increased number of these types of cases brought against dentists in recent years has become a major problem in this country $[3,4]$. The reason for that may be that patients are more aware of their own rights or because the new laws have been passed or revised regarding malpractice. However, most of the results of the malpractice cases sent to the courts are not known.

During the investigation of the reports regarding the missing papers, it was found out that the dentists did not have enough information about managing malpractice cases and how to prepare for a forensic report in case of one. This lack of information causes problems for the dentists during their defense in malpractice cases $[5,6]$.

In the investigated files, especially concerning of trauma and malpractices, the lack of forensic odontology knowledge and experience of dentists is pointed out obviously. In conclusion, the results of this study suggested that Forensic odontology lectures should be more effective and be separately given in addition to the lectures on General Forensic Medicine in Dentistry Faculties. In this respect existing situation demand that, sufficient courses should be organized for the graduated dentists and new lectures should be arranged to the dentistry students.

\section{Acknowledgements}

This study was supported by the Research Fund of Istanbul University. Project Number: UDP: 3109/09042009. We would like to thank the Dentistry Faculty Dean Professor Hasan Meric who gave us permission to work with the staff of the department in the archive of the deanship.

The authors would like to thank Mr. Fuat Karaman for his professional assistances of editing the translation.

\section{References}

1. Borrman H, Dahlbom U, Loyola E, René N (1995) Quality evaluation of 10 years patient records in forensic odontology. Int J Legal Med 108: 100-104.

2. Avon SL (2004) Forensic odontology: the roles and responsibilities of the dentist. J Can Dent Assoc 70: 453-458.

3. Ozdemir MH, Saracoglu A, Ozdemir AU, Ergonen AT (2005) Dental malpractice cases in Turkey during 1991-2000. J Clin Forensic Med 12: 137-142.

4. Conrad DA, Whitney C, Milgrom P, O'Hara D, Ammons R, et al. (1995) Malpractice premiums in 1992: results of a national survey of dentists. J Am Dent Assoc 126: 1045-1056.

5. Eijkman MA, Assink MH, Hofmans-Okkes IM (1997) Defensive denta behaviour: illusion or reality? Int Dent J 47: 298-302.

6. Keeling SD, Martin CS (1990) The malpractice morass and practice activities of orthodontists. Am J Orthod Dentofacial Orthop 97: 229-239. 